\title{
К проблеме эволюции пространственных форм архитектуры в контексте научно-технологических достижений
}

\author{
Н.В.Касьянов, НИИТИАГ, Москва
}

Для архитектурной теории важно изучение фундаментальных механизмов формообразования и самой формы в контексте современных данных и концепций различных областей науки. Подходы, используемые классической геометрией и «новыми», неевклидовыми геометриями могут быть в определённой мере применены для развития пространственного потенциала архитектуры и градостроительства. Инновационные пространственные формы возникают и развиваются на стыке науки и искусства, инженерии и зодчества. Рассматриваемая область исследований связана с различными научными областями и специализациями, включающими геоинформатику, биологию, математику, кристаллографию, инженерную геометрию и компьютерное моделирование. Инновационные технологии и новый инструментарий научной и практической работы проектировщика меняют принципы и концепции построения архитектурного пространства. В частности, проектирование чрезвычайно сложных с геометрической точки зрения конструкций было бы невозможным без развития компьютерных технологий. Междисциплинарный подход позволяет выявить спектр неизвестных ранее геометрических форм, вариантов заполнения и разбиения двумерной поверхности и трёхмерного пространства. Интеграция и конвергенция научных достижений, инженерного искусства и архитектуры нередко ведут к возникновению новаторских форм. Основные геометрические закономерности едины в живой и неживой природе в естественном и антропогенном мире, включая архитектуру, от микро-до макроуровня; при этом современное экологическое мышление осознаёт земную биосферу как интегрированное целое. Исследования актуализируются наступлением нового технологического уклада и синтезом технологий, размывающим границы между виртуальным и физическим миром. Данная тема носит теоретический характер; потенциально возможно применение результатов в учебной практике и экспериментальном проектировании ${ }^{1}$.

Ключевые слова: формообразование и геометрия архитектуры, природный морфогенез, междисциплинарный подход, компьютерное моделирование, заполнение и разбиение пространства, инновационная и виртуальная архитектура.

${ }^{1}$ Статья подготовлена в рамках выполнения фундаментального научного исследования за счёт средств Государственной программы Российской Федерации «Развитие науки и технологий» на 2013-2020 годы по Плану фундаментальных научных исследований Минстроя России и РААСН, тема 1.4.6. «Технологии и проблемы формообразования в архитектурной теории и учебном процессе».
To the Problem of the Evolution of Architectural Spatial Forms in the Context of Scientific and Technological Achievements

N.B.Kas'yanov

For architectural theory it is important to study the fundamental mechanisms of shaping and the form itself in the context of modern data and concepts of various fields of science. The approaches used by classical geometry and "new", non-Euclidean geometries can be applied to a certain extent to the development of the spatial potential of architecture and urban planning. Innovative spatial forms arise and develop at the intersection of science and art, engineering and architecture. This work is related to various scientific fields and specializations, including geoinformatics, biology, mathematics, crystallography, engineering geometry and computer modeling. Innovative technologies and new tools of scientific and practical work of the designer are changing the principles and concepts of building architectural space. In particular, the design of extremely complex (from a geometric point of view) structures would be impossible without the development of computer technologies. The interdisciplinary approach allows us to reveal a spectrum of previously unknown geometric forms, options for filling and splitting a two-dimensional surface and three-dimensional space. The integration and convergence of scientific achievements, engineering and architecture often leads to the emergence of innovative forms. The main geometric patterns are the same in animate and inanimate nature - in the natural and anthropogenic world, including architecture, from micro to macrolevel; at the same time, modern ecological thinking is aware of the terrestrial biosphere as an integrated whole. Researches are updated by the onset of a new technological approaches and the synthesis of technologies, blurring the boundaries between the virtual and physical world. This study is theoretical; potential application of the results in educational practice and experimental design is possible.

Keywords: architectural shaping and geometry, natural morphogenesis, interdisciplinary approach, computer modeling, space filling, spatial tessellation, innovative and virtual architecture.

Фундаментальная наука исследует законы природы; её открытия непредсказуемы, но именно они порождают важнейшие, важные практически инновационные направления. 
Наука определяет контуры будущего, хотя прогноз всегда носит вероятностный характер [1]. Новый технологический уклад, глобализация, цифровая революция, изменение эстетических представлений в рамках экологической парадигмы неизбежно оказывают влияние на архитектурное формообразование. Современное экологическое мышление осознаёт земную биосферу как интегрированное целое, единую сеть взаимодействующих друг с другом и неживой природой организмов и антропогенных объектов [2; 3]. Формообразующий потенциал архитектурной и инженерной организации пространства далеко не исчерпал своих возможностей. Для теории архитектуры важны исследования глубинных механизмов формообразования в свете новейших тенденций и достижений современной науки. Современные достижения науки были бы невозможны без развития компьютерных технологий, давших возможность проектирования чрезвычайно сложных с геометрической точки зрения конструкций. Новый инструментарий научной и практической работы проектировщика и инновационные технологии меняют принципы и концепции построения архитектурного пространства. Поставленные задачи включают анализ существующих архитектурных форм, поиск алгоритмов и адекватных моделей архитектурного формообразования, применение компьютерного моделирования в экспериментальном архитектурном проектировании. Архитектура и дизайн являются областью практического приложения математических концепций пространственных разбиений. Формообразование вовлекает множество разнообразных структур, анализируемых с учётом конвергенции научных концепций и терминологии таких научных областей и специализаций, как геоинформатика, биология, математика, кристаллография, инженерная геометрия и компьютерное моделирование, что превращает проводимые исследования в междисциплинарные.

Устойчивость любой структурной формы основывается на геометрической сущности, биохимической реализацией которой является живое существо [4]. Морфология стремится к форме, предельно устойчивой и инвариантной во времени. Энтропия - абстрактная мера неупорядоченности. Каждый организм стремится к достижению оптимальной меры негэнтропии как отрицательной информации. «0пираясь на морфогенетический параллелизм в природе, вооружившись принципами теории автоэволюции, мы можем связать существование паттернов с общим законами природы и со структурой вселенной» [цит. по 5, с. 246]. Общие закономерности природы включают, например, гномонический, фрактальный рост и ветвление, аллометрию, эмерджентность как возникновение новых свойств системы $[4 ; 5 ; 6]$.

Структурный подход в морфологии означает признание только эмпирической морфологии; его цель - упрощение эмпирического описания посредством выявления скрытых закономерностей и симметрий. Некоторые процессы (гидродинамическая турбулентность, фрактальные явления) включают изоморфное повторение, итерацию. В некоторых процессах морфологического формообразования возможно множество изоморфных уровней организации, бесконечность изоморфных друг другу уровней фрактальной организации (кривая фон Коха, множество Кантора - реализации этой счётной бесконечности) [4;6].

Математический подход к описанию и анализу формообразования и соответствующая интерпретация некоторых морфогенетических событий с использованием концепций и теорем топологии выявляют неизбежность возникновения сингулярностей, неоднородностей в ходе формообразования, топологические ограничения набора возникающих паттернов, неразрывную связь локальных и глобальных аспектов формообразования [1; 4; 7]. Ряд проблем формообразования могут быть решены топологически, поскольку именно топология позволяет переходить от локального порядка к глобальному.

Идеи теории катастроф (бифуркаций) Рене Тома одновременно математически строги и приложимы ко многим областям наук. Бифуркация означает переход системы на иную траекторию дальнейшей эволюции; точка бифуркации - неустойчивое состояние нелинейной системы с потенциальной возможностью изменения будущего развития. Наиболее известные основоположники нелинейной динамики как современной научной парадигмы и методологии исследований - А. Пуанкаре (1854-1912), А.А. Андронов (1901-1952), А.Н. Колмогоров (1903-1987), И. Пригожин (1917-2003), Г. Хакен (р. 1927), Р. Том (1923-2002), В.И. Арнольд (1937-2010).

Возрождение и развитие бионики, биомиметики и идей органической архитектуры, использование аналогов природных конструкций, выдвижение новых архитектурных идей, применение компьютерных и телекоммуникационных технологий, а также концепций нелинейной динамики может способствовать развитию архитектуры и инженерии XXI века на новом теоретическом и технологическом уровне. Инженерно-архитектурное разнообразие правомерно рассматривать как некое подобие природного биоразнообразия.

\section{Исторический очерк геометрических исследований}

Геометрия является важнейшей, фундаментальной составляющей архитектурного формообразования. Тысячи лет назад греческие философы открыли миру пять Платоновых многогранников - класс геометрических форм, грани которых образованы одинаковыми правильными многоугольниками. Такие многогранники - тетраэдр, гексаэдр, октаэдр, додекаэдр и икосаэдр - имеют соответственно 4, 6, 8, 12 и 20 граней и обладают пространственной симметрией. Почти все эти регулярные структуры встречаются в природе в виде различных кристаллов. Далее были открыты Архимедовы тела (которые включают усечённый икосаэдр, напоминающий футбольный мяч). Астроном и математик Иоганн Кеплер (1571-1630) провёл системное исследование многогранников и открыл два первых звёздчатых многогранника, применив для их 
построения расширение граней исходных многогранников додекаэдра и икосаэдра (рис. 1, 2).

Леонардо да Винчи (1452-1519) первым изобразил многогранники с прозрачными гранями, так что зрителю были видны их рёбра, расположенные сзади; он показал также группы многогранников. Альбрехт Дюрер (1471-1528) в 1525 году применил методы перспективы, представив многогранники с прозрачными гранями и создав их первые развёртки.

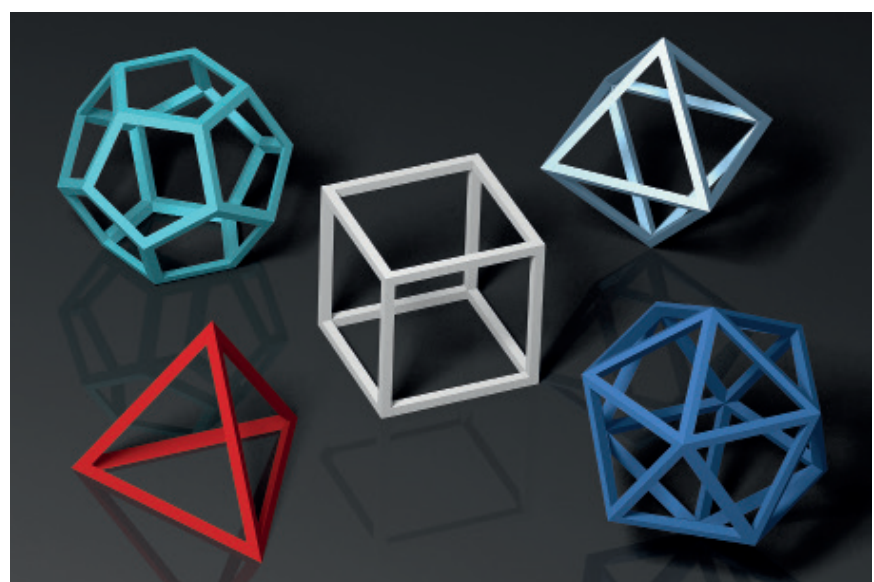

Рис. 1. Пять Платоновых тел, с которыми исходно пытались связать природные стихии

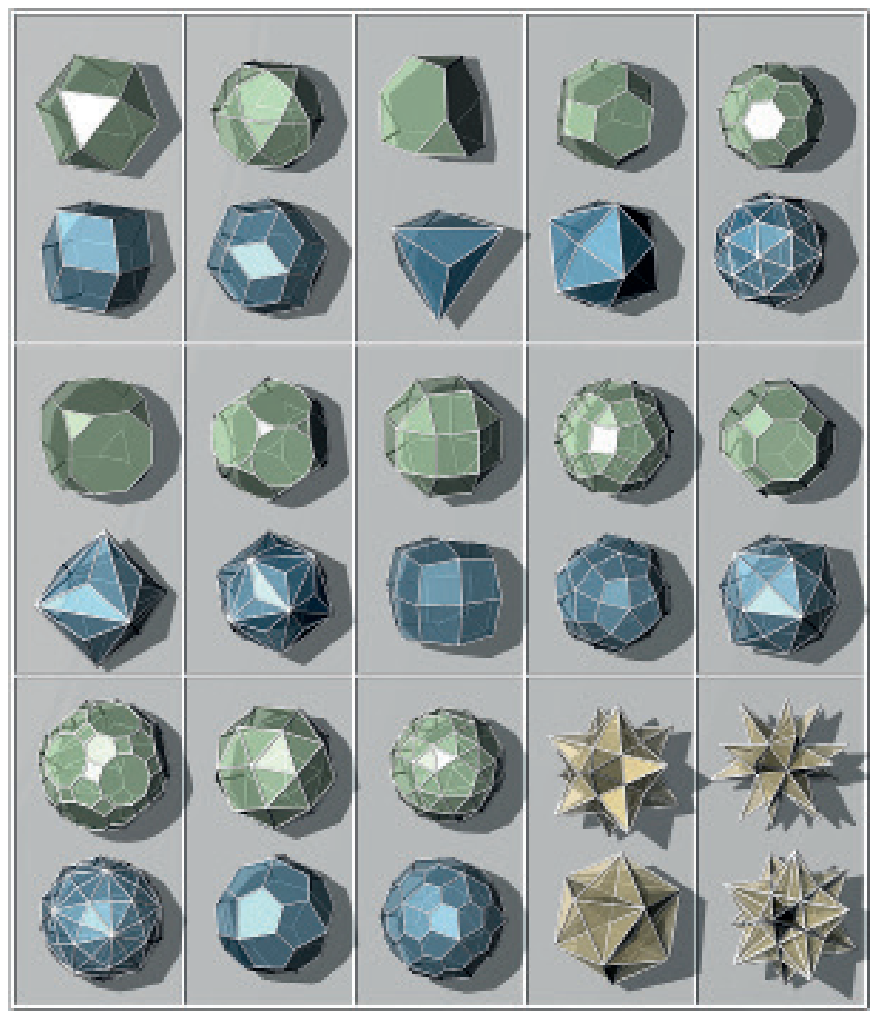

Рис. 2. Архимедовы тела (показаны зелёным), Каталановы тела (синим), тела Кеплера и Пуансо (жёлтым). Правая фигура в верхнем ряду -усечённый искосаэдр, соответствующий морфологии молекулы фуллерена. Вторая и третья фигуры в пятом ряду- «плосконосые» куб и додекаэдр, обладающие поворотной симметрией
Формула, сыгравшая огромную роль при изучении многогранников, была открыта российским академиком Леонардом Эйлером (1707-1783): сумма числа граней и вершин многогранника равна числу его рёбер, умноженному на два.

Создатель начертательной геометрии Гаспар Монж (1746-1818), подобно художникам Возрождения, использовал многогранники в качестве идеальных моделей при работе

${ }^{2}$ Автор компьютерной графики и фотографий Н.В. Касьянов

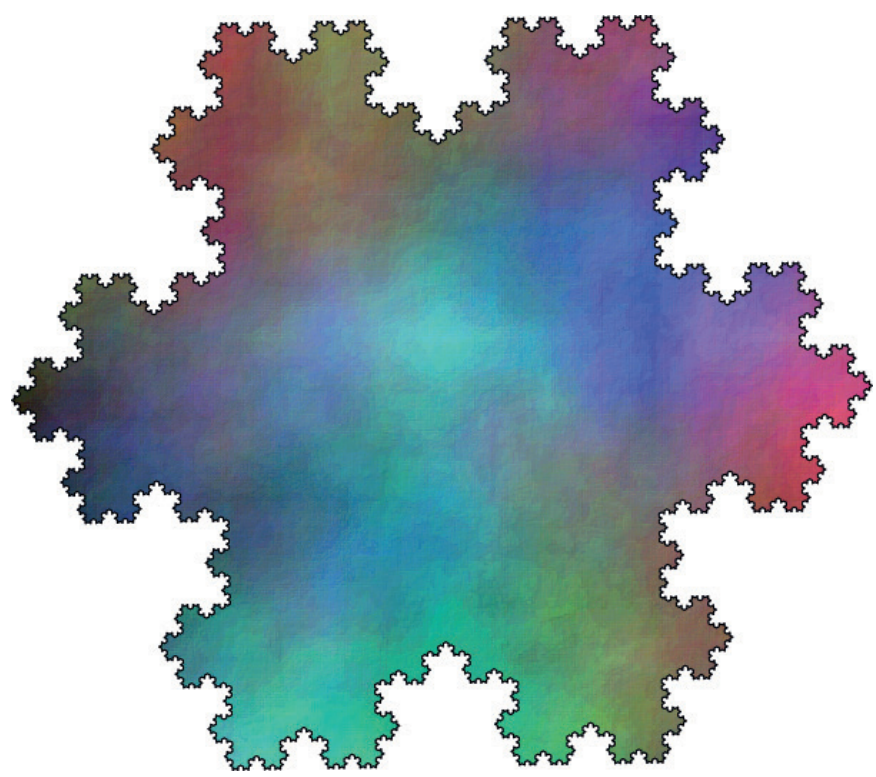

Pис. 3. Множество фон Коха, позволяющее математически описывать некоторые фортификационные сооружения прошлого, проекты «идеальных» городов и иных звездчатых структур

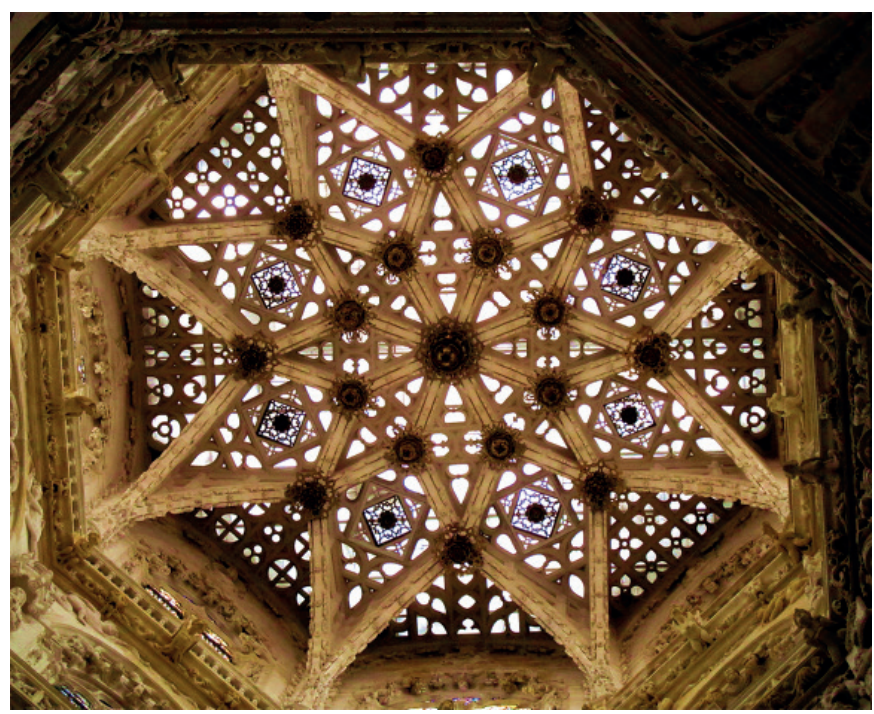

Рис. 4. Звездчатая структура в подбашенном пространстве кафедрального собора в Бургосе, памятника всемирного наследия ЮНЕСКО. Испания. Фото 2017 года 
над своей теорией [8]. Монж был одновременно военным инженером, и его разработки в области фортификации весьма существенны. Следует заметить, что именно фортификация породила целый спектр необычных и весьма оригинальных форм, которые архитекторами обычно не рассматриваются (рис. 3, 4). Французский математик и физик Луи Пуансо (1777-1859), помимо своих открытий в области механики, изучал многоугольники и многогранники и описал два новых звёздчатых многогранника, названных телами Пуансо. Не-

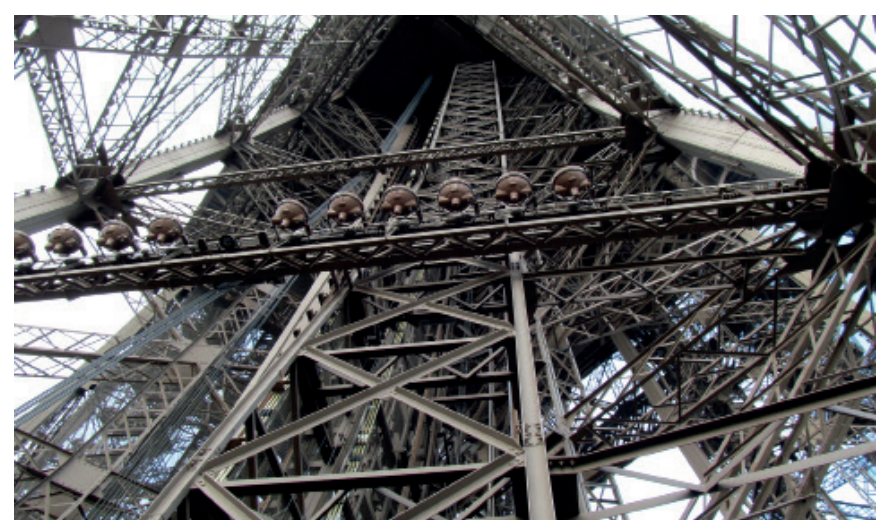

Рис. 5. Внутренняя структура Эйфелевой башни. Париж, Франция

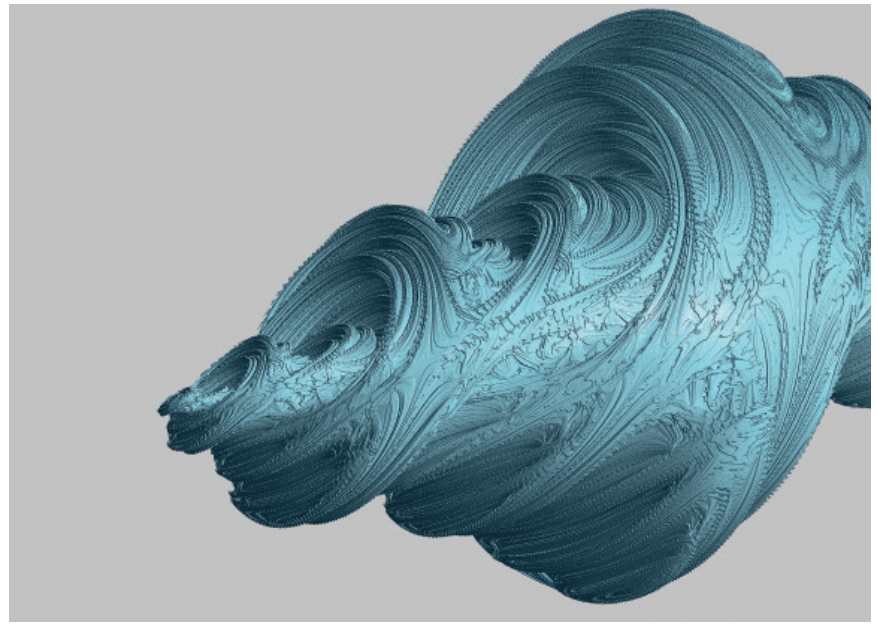

Рис. 6. Пример визуализации поверхности трёхмерного фрактального аттрактора

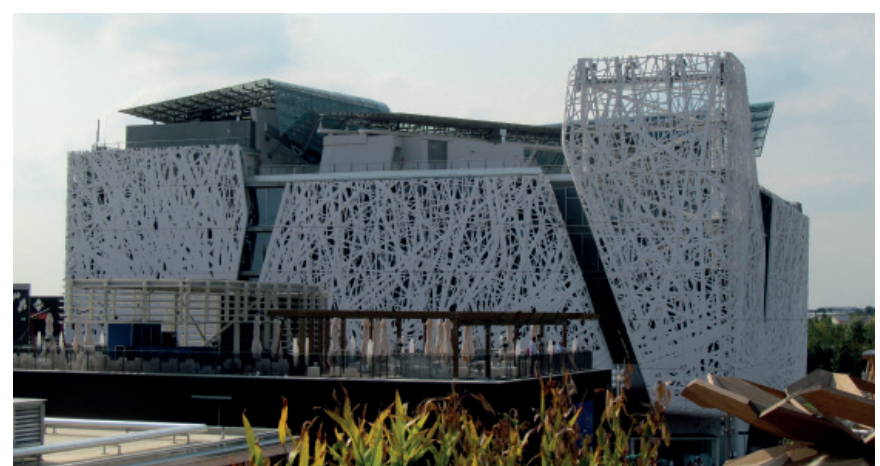

Puс. 7. Павильон Италии на выставке Экспо-2015. Пример архитектурного решения, которое может быть интерпретировано как визуализация с использованием одного из алгоритмов динамического хаоса. Милан, Италия. Фото 2015 года сколько позже были открыты Каталановы тела [Эжен Шарль Каталан (1814-1894)].

Российский и советский математики Г.Ф. Вороной (1868-1908) и Б.Н. Делоне (1890-1980) создали новые математические методы разбиения поверхности (такие как диаграмма Вороного и триангуляция Делоне), напоминающие некоторые «хаотические» природные структуры. Подобными исследованиями занимался и И. Дирихле (1805-1859), член многих академий наук, включая Петербургскую.

На протяжении полуторавековой истории развития сетчатых металлоконструкций их эволюция во многом была обусловлена достижениями подвижников, работавших на стыке инженерии и архитектуры. Геометрически сложные пространственные конструкции из металла начали появляться в середине XIX века, одним из ярких проявлений стал «Хрустальный дворец» Д. Пакстона. Несколько позже в Европе появились архитектурно-инженерные конструкции Г. Эйфеля (рис. 5).

В России к концу XIX века В.Г. Шухов стал основоположником многих революционных строительных конструкций, стремясь к синтезу инженерии и архитектуры и впервые создав сетчатые гиперболоидные башни, подвесные и сводчатые покрытия. Он освоил искусство конструирования с минимальными затратами на материал и монтаж. Сетчатые оболочки и башни в форме гиперболоида были решениями нового типа, сочетавшими лёгкость, простоту и элегантность. Таким образом, необычные и смелые формы металлоконструкций трансформировали инженерно-конструктивные системы в архитектурные решения.

Антонио Гауди (1852-1926) черпал вдохновение в природе и проводил эмпирические опыты, анализируя построение пространственных геометрических форм, в течение всей жизни. Изучая начертательную геометрию, Гауди узнал о многогранниках и кристаллографических группах и конструировал модели многогранников (см. рисунок на 4-ой странице обложки).

Немецкий инженер Фрей Отто создавал и активно развивал различные типы висячих сетчатых покрытий, комбинированных с мембранами и сводчатыми конструкциями. Уже во второй половине XX века появились каркасно-мембранные конструкции.

Если геометрия Евклида реализуется на поверхностях с постоянной нулевой гауссовой кривизной (плоских поверхностях), Лобачевского - с постоянной отрицательной, то геометрия Римана реализуется на поверхностях с постоянной положительной гауссовой кривизной, то есть на сферах. К началу 1980-х возникла «Фрактальная геометрия природы» Б. Мандельброта [6], демонстрирующая математическую основу огромного структурного разнообразия природных форм (рис. 6, 7).

Поиском новых форм многогранников, звёздчатых и «склеенных» друг с другом, описанием построения таких форм и свойств их симметрии занимались такие известные 
математики, как М. Брюкнер, А. Уилер и другие. Математик Давид Гилберт (1862-1943) в своём известном выступлении в Париже в 1900 году в числе основных математических проблем XX века упомянул и задачи о многогранниках. Гарольд Скотт Макдональд Кокстер (1907-2003) ввёл новые понятия, обобщения и многомерные расширения многогранников; он открыл 12 новых однородных многогранников и создал описание 59-ти фигур, изучив возможные построения звёздчатых конфигураций. Будучи увлечённым музыкой, Кокстер говорил, что свои книги по геометрии многогранников выстраивает подобно симфонии. Он обладал мощным пространственным воображением и исследовал многогранники в многомерных пространствах (политопах). В частности, гиперкуб теоретически определяется восемью кубами, которые являются его трёхмерными гранями, имеет 24 двумерные грани, 32 одномерных и 16 нульмерных граней [8].

Существуют немногочисленные примеры урбанистического воплощения подобных абстрактно-концептуальных форм. Это памятник Конституции в Мадриде в виде белого бетонного куба со стороной 7,75 м, визуализирующего гиперкуб, и Большая Арка Дефанс в Париже, подобная гиперкубу, строительство которой было завершено в 1989 году. Таким образом, визуализация абстрактной математической концепции гиперпространства уже послужила метафорой гуманитарных идей (рис. 8).

Тема абстрактной геометрии в творчестве Морица Корнелиуса Эшера возникла благодаря его сотрудничеству с Гарольдом Кокстером. В итоге Эшером были изображены невозможные в реальности пространства и фигуры, укладки и мозаики. По сути, Эшер был ближе к математикам, а не к коллегам-художникам. Он ещё в 1920-е годы познакомился с узорами Альгамбры (рис. 9) и в своих работах использовал 17 групп симметрии на плоскости, позднее изучив способы сочетать цвет, фигуры и

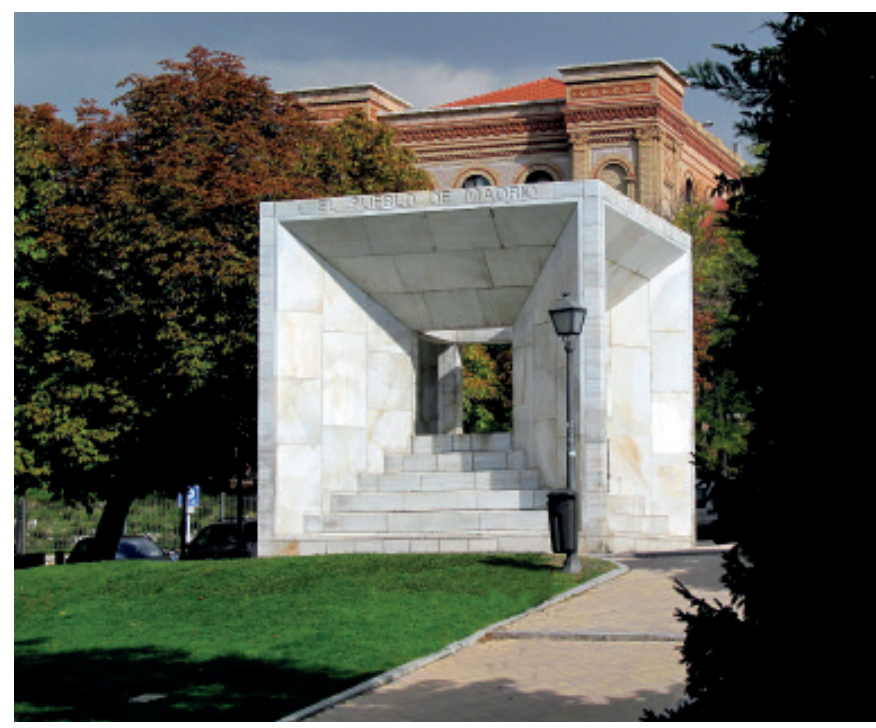

Рис. 8. Памятник Конституции в Мадриде, геометрически символизирующий гиперкуб. Испания. Фото 2014 года симметрию, интегрируя тем самым математику и искусство. По словам Кокстера, в этих работах Эшер достиг вершин своего искусства, инстинктивно создавая их [8].

Шведский художник Оскар Рутерсвард внёс заметный вклад в коллекцию невозможных фигур, создав около 2500 таких фигур, включая множество новых невозможных многогранных структур [9].

\section{Геометрия архитектурной формы в контексте совре- менного научного знания}

Подавляющее большинство инженерных и архитектурных объектов -утилитарные и невзрачные ортогональные «коробки» или «пластины». Уход от рутины традиционного мышления - удел новаторов архитектуры и инженерного искусства. Это порождает перспективы в инновационном формообразовании общественных зданий и технических сооружений, которые могут быть более художественно осмысленными. Возможно, новые материалы, создаваемые с применением нанотехнологий, новые сплавы, углепластики позволят совершить эволюционный шаг в архитектонике архитектурных объектов и инженерных сооружений.

В настоящее время известно более пятисот геометрических поверхностей почти сорока классов, потенциально применимых в архитектурно-строительной сфере: линейчатые (нулевой, положительной и отрицательной кривизны), поверхности вращения разных типов, спиральные, зонтичные, седловидные, кинематические, алгебраические поверхности нескольких порядков, квазимногогранники и т.д. Можно упомянуть также складчатые системы, гиперболоидные, сводчатые и купольные формы, включая геодезические [10]. Пока далеко не все из этих форм нашли своё место в архитектуре. В значительной степени это связано отнюдь не с технической сложностью реализации, а с незнанием проектировщиками возможностей формообразования, обусловленным недостаточным внима-

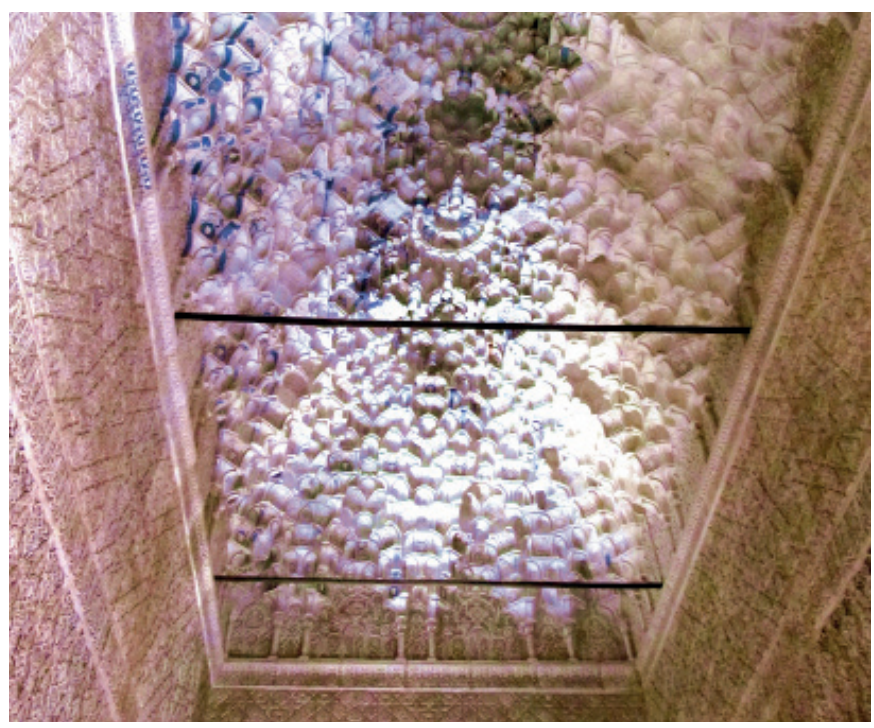

Рис. 9. Мавританский декор одного из залов Альгамбры в Гранаде. Испания. Фото 2014 года 
нием к соответствующим дисциплинам при обучении. Можно вспомнить эпоху советского архитектурного авангарда, когда концепции архитектурного формообразования опережали развитие технологических возможностей реализации этих концепций. Ныне осуществляется очередной виток научнотехнологического развития, и отстаёт порой уже осознание новых возможностей архитекторами и обществом в целом.

Общие принципы формообразования на микро-, мезои макроуровне в различных системах можно выявить путём сопоставления морфогенеза в архитектуре и биологии, технике, кристаллографии. Внедрение в архитектуру достижений других областей науки и их метафор может обеспечить качественный скачок в формообразовании и функционировании новой архитектуры. Область архитектуры и дизайна является и практическим приложением математических концепций пространственных разбиений. При создании крупных архитектурных форм для воплощения художественного замысла и решения конструктивных задач могут быть использованы различные полигональные структуры, а также многогранники.

Во многих архитектурных проектах начала 2000-х происходил постепенный отход от правильного и симметричного разбиения поверхности и пространства к биоморфному, по алгоритму Вороного-Дирихле [11]. Хаотично или псевдохаотично расположенные ячейки складываются в естественный узор, подобный структурам живых клеток (рис. 10).

Р.Б. Фуллер, американский изобретатель, получивший патент на конструкции в виде треугольников, составляющих полусферу или сфероид, которые можно использовать как покрытие больших сооружений, постулировал принципы минимакса и «замещение материала информацией» [12]. Был сформулирован фундаментальный способ самоорганизации целостной системы, получивший название «тенсегрити» (tensegrity) - этот термин составлен из двух усечённых: слов: tension (напряжение, натяжение) и integrity (целостность). Термин «тенсегрити» был

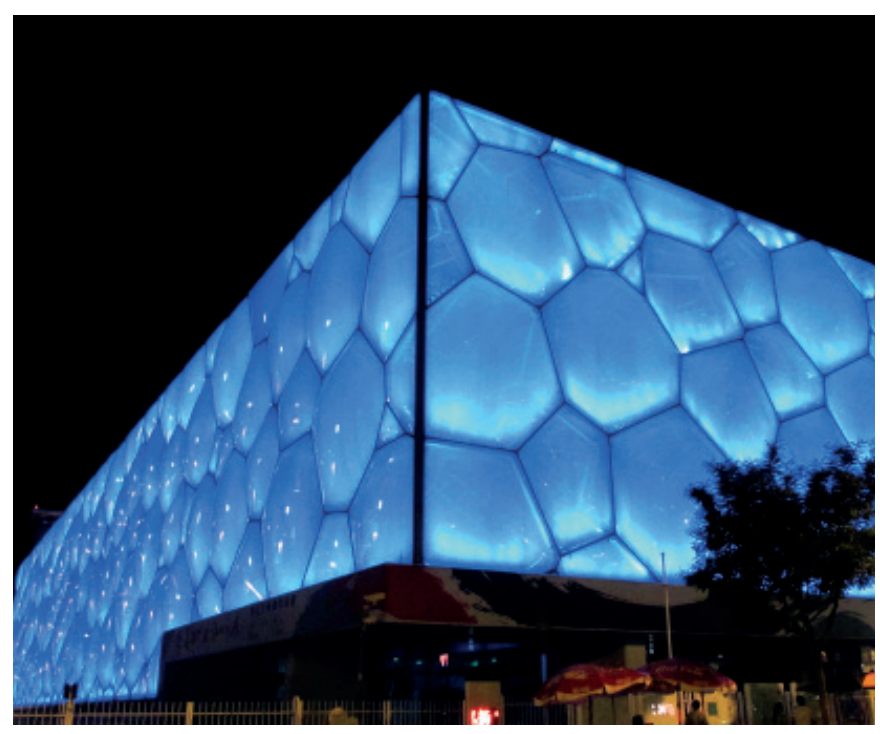

Рис. 10. «Водный куб»/Пекин, Китай. Фото 2013 года применён и кобъяснению свойств устойчивого, механически напряжённого, интегрированного цитоскелета живой клетки [4; 13; 14]. Устойчивость свода геодезического купола обеспечивается упругим равновесием системы, обеспечивающим прочность конструкции за счёт эффекта тенсегрити при относительно малом расходовании материалов. В СССР такими разработками занимался проф. МАРХИ М.С. Туполев. Разбиение поверхности осуществляется на основе платоновых тел, как правило, икосаэдра, додекаэдра или их комбинации.

Принципы разбиения и замощения поверхности - область прежде всего математики и топологии. Единые закономерности топологической организации нашего мира кратко и корректно формулируются математически, например, теоремами Эйлера, Гаусса-Бонне, Брауэра. В частности, неизбежность появления немногих пятиугольников в сети шестиугольников на сфере общая закономерность топологической организации нашего мира. Из теоремы Эйлера следует, что возможно лишь пять правильных многогранников (Платоновых тел) и правильных графов на сфере, и это одно из чисто топологических ограничений. В иных случаях топологически неизбежно возникает неоднородность дискретного поля разбиения поверхности сферы [15]. Таким образом, однородное разбиение поверхности возможно на плоскости и торе (поверхность тора может быть полностью замощена шестиугольниками), но не на сфере. Неизбежность неоднородного паттерна на сфере - следствие топологии нашего трёхмерного мира.

В 1985 году группа исследователей (Г.В. Крото и др.) открыла новую форму углерода, молекулы которого образуют замкнутую поверхность в форме сферы или вытянутого сфероида, на которой располагаются атомы углерода [16]. В 1996 году авторы открытия получили Нобелевскую премию по химии. Характерно, что они не могли понять строение молекулы новой формы углерода, пока не узнали о работах Р. Фуллера. Исследователи дали новому соединению имя фуллерен, хотя эта форма восходит ещё к древнегреческому инженеру, физику и математику Архимеду.

Помимо стандартных геодезических раскладок фуллеровского типа, стали появляться новые варианты, включающие поворотную симметрию. Они создаются на основе так называемых «плосконосых» фигур со скошенной, смещённой или скрученной симметрией. Соответственно, закрутка может быть по часовой стрелке или против неё, с возникновением правосторонней и левосторонней симметрии. В животном мире раннее развитие некоторых животныхпроисходит с подобным смещением клеток верхней полусферы относительно нижней по часовой стрелке (дексиотропное смещение) или наоборот (леотропно); дексиотропные и леотропные деления чередуются.

И в наше время происходит открытие новых трёхмерных геометрических фигур с поворотной симметрией. Исследователи, совершившие одно из недавних открытий, вдохновлялись, как ни странно, человеческим глазом. Стэн Шейн из Калифорнийского университета в Лос-Анджелесе изучал сетчатку глаза, когда его заинтересовала структура молекулярного комплекса 
белка, называемого клатрином. Белок участвует в транспортировке ресурсов из клетки и в клетку, образуя небольшое количество форм. Формы эти заинтересовали Шейна, и в итоге он вывел математическое объяснение этого явления. В ходе своей работы учёный случайно натолкнулся на исследования математика Майкла Голдберга (1902-1990). Голдберг в 1937 году описал ряд новых форм, которые и были названы в его честь - многогранники Голдберга [17]. И вот теперь исследователи из США утверждают, что открыт новый, четвёртый класс многогранников [18]. Кроме того, они полагают, что это открытие свидетельствует о вероятности существования бесконечного числа таких классов. Это весьма вероятно, поскольку существует множество разнообразных вариантов разбиений, и многие из них ещё не были построены и исследованы.

В октябре 2010 года первооткрывателям графена, А.К. Гейму и К.С. Новосёлову, работающим в Университете Манчестера, была присуждена Нобелевская премия по физике. Кристаллическая решётка графена представлена плоскостью, состоящей из шестиугольных ячеек, то есть является двумерной гексагональной кристаллической решёткой. Графен можно представить как одну плоскость графита, отделённую от объёмного кристалла, слой углерода толщиной в один атом [19]. Подобные структуры в масштабе архитектурных сооружений перспективны как в инженерном, так и в художественном отношении.

В основе формирования многих комплексных природных структур лежит минимизация затрат энергии за счёт образования тройных узловых точек и уменьшения поверхностей контактирующих элементов с появлением топологически устойчивых конструкций. Закономерности стыковки, контактов поверхностей едины для нашего трёхмерного мира - для биологии, кристаллографии и архитектуры. Примерами и средством моделирования соприкасающихся минимальных поверхностей могут служить сростки кристаллов, мыльные пузыри. Задача плотной упаковки геометрических тел является одной из классических задач математики. При достаточно сильном давлении плотно упакованные деформируемые шары превращаются в многогранники. Возможны плотные варианты упаковки тетраэдров, икосаэдров, додекаэдров и октаэдров, однако 100-процентное заполнение трёхмерного пространства без искажения формы этих многогранников не реализуемо. В частности, плотно прилегающими друг к другу тетраэдрами нельзя «выложить» всё пространство. Задача деления трёхмерного пространства на равные многогранники, которую решил математик Уильям Томсон Кельвин, получивший титул барона Кельвина (William Thomson, 1st Baron Kelvin; 1824-1907), приводит к 14-граннику. В 1993 году Дэнис Уэйр и Роберт Фелан предложили разбиение с меньшей площадью, чем у разбиения, ранее предложенного Кельвином. В него входят два рода фигур - многогранники с 12-ью и 14-ью гранями [20] (рис. 11).

Квазикристаллы впервые исследовал Даниэль Шехтман в экспериментах по дифракции электронов сплавом $\mathrm{Al}_{6} \mathrm{Mn}$ при его быстром охлаждении, проведённых в 1982 году [21], за что ему в 2011 году, после длительного непризнания, была присвоена Нобелевская премия по химии. Для квазикристаллов характерна пятилучевая симметрия, «запрещённая» в канонической кристаллографии, но распространённая в мире растений и животных. Помимо пятилучевой симметрии, исследования квазикристаллов кристаллографами выявили другие - невозможные, казалось бы, - паттерны с осевой симметрии 7-го, 8-го, 10-го, 12-го и ещё более высоких порядков, «запрещённые» для идеальных кристаллов. Паттерны, полученные Шехтманом, подобны так называемым апериодическими мозаикам Пенроуза [21]. Подобные структуры уже применялись в орнаментальном декоре, теперь же становится возможным их использование в формировании пространственных композиций.

Изучение филлотаксиса растений представляет собой мультидисциплинарную область исследований [5]. В филлотаксисе обнаруживается последовательность Фибоначчи, то есть рекурсивная, фрактальная математическая функция [22]. Таким образом, в основе бесконечного многообразия морфологии ветвящихся форм растений заложены математические константы [23]. Паттерн филлотаксиса - оптимальная конструкция плотной упаковки элементов. Биологические структуры, оптимальные в контексте естественного отбора, являются также оптимальными в отношении минимизации функциональных затрат. Паттерны филлотаксиса являются решениями задач оптимальности, предложенными природой. Пятикратная симметрия - одна из главных характеристик филлотаксиса [5].

\section{Перспективы междисциплинарных исследований} формообразования и развития среды обитания

Морфологию новой архитектуры формируют многочисленные внешние факторы в сочетании с внутренней логикой и закономерностями пространственной организации. По сути, возникла новая морфотектоническая типология зданий, основанная на математических принципах, нередко псевдобиоморфных. Зодчие порой сознательно прибегают к цитированию и имитации природных форм или их фрагментов. Инженеры и архитекторы создают динамичные, «текучие» формы, геоморфные и биоморфные структуры. Технология лазерного сканирования сложных форм позволяет создать «облако точек», описывающих геометрию объекта. Параметрические методы

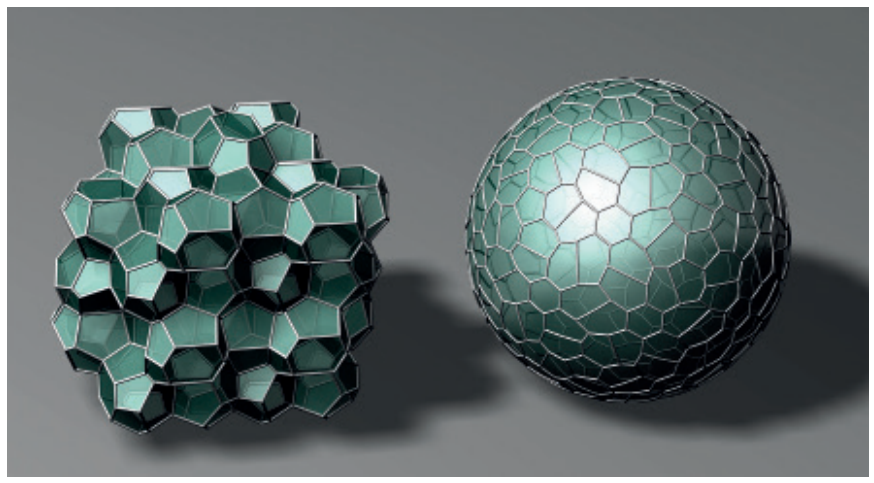

Рис. 11. Примеры кристаллоподобной и биоморфной структур, применимых в архитектуре 
генерации позволяют управлять такой геометрией, структурируя и корректируя её по определённым математическим правилам. Новые градостроительные образования могут генерироваться параметрически, оптимизируя пересечения потоков людей и взаимодействие различных структур. Ряд такого рода формообразующих концепций и структур был ранее описан автором в статьях [24].

К концу XX века на стыке компьютерных и биологических исследований возникла новая междисциплинарная наука, включающая изучение и математическое моделирование жизни в компьютере («in silico») [25]. Кристофер Лэнгтон (C. Langton) назвал эту науку, созданную им и другими сотрудниками национальной лаборатории Лос Аламоса (Los Alamos National Laboratory), Искусственной Жизнью (Artificial Life). Лэнгтоном дано и определение новой науки: «Artificial life - изучение искусственных систем, проявляющих поведение, характерное для природных живых систем. Оно включает компьютерное моделирование, биологические и химические эксперименты и чисто теоретические поиски. Объекты исследования - процессы на молекулярном, клеточном, нейральном, социальном и эволюционном уровнях. Конечная цель - понять логические формы живых систем» [26]. Возникло и понятие reverse engineering - исследование устройства с целью понимания его работы для воспроизведения функций.

Математическое моделирование и развитие искусственной жизни и систем искусственного интеллекта вносят всё больше новаций как в повседневную жизнь, так и в архитектуру, которая в своём развитии все чаще взаимодействует с областями технической эстетики и дизайна. Информационные технологии стали мощнейшим инструментарием, придавшим серьёзный импульс социально-экономическому развитию человечества, появлению новых и расширению существующих областей науки. Технологические преобразования и их скорость зачастую носят революционный характер. Многие идеи и футурологические возможности этого направления исследований порождают вопросы; современные попытки ответов на них носят порой дискуссионный и противоречивый характер. Каким будет дальнейшее совместное развитие информационного общества и архитектуры?

Приближаясь к природе по формообразованию и идеологии, архитектура по-прежнему остаётся не живой, а лишь имитирующей живую природу. Впрочем, не исключено, что на каком-то этапе совершенствование технологий приведёт к тому, что некие структуры, например, претерпевающие биоминерализацию, будут использоваться и в конструкциях будущих зданий. Многие инновационные идеи для архитектуры и дизайна, связанные с теорией самоорганизации, вполне реализуемы в настоящее время на уровне экспериментальных проектов и поисковых технических решений. В то же время периодически возникают новые идеи и, возможно, миражи, диктуемые вызовами нового технологического уклада. Использование информационных технологий, достижений робототехники, принципов природной самоорганизации и синтез этих подходов - эффективный путь построения сложных систем, определяемый внутренними свойствами их компонентов. Что касается технологий трёхмерной печати, то уже совершенно очевидно, что они получают применение во всех развитых странах, так как позволяют изменить характер производства целого ряда изделий различного назначения. В частности, эти технологии перспективны при создании домов для беженцев и переселенцев, в районах чрезвычайных ситуаций и экстремальных условий. Научные разработки и исследования в области искусственных нейронных сетей и интеллекта позволяют по-новому взглянуть на идеи создания «умных домов», интеллектуальной и интерактивной архитектуры. Это создаёт дополнительные возможности по формированию более комфортной среды, функционирующей и взаимодействующей с людьми на принципиально ином качественном и технологическом уровне. Начало XXI века ознаменовалось активным развитием единого информационно-энергетического поля и глобализацией социально-экономического пространства. Распространение и относительное удешевление технических средств контроля и совершенствования информационных сетей позволяют организовать круглосуточный мониторинг состояния объектов с целью обеспечения их безопасности. Архитектура и дизайн, несомненно, уже оказываются под массированным влиянием подобных концепций, и возможные последствия должны быть подвергнуты дальнейшему анализу и изучению.

$$
* * *
$$

Для теории архитектуры важны исследования глубинных, фундаментальных механизмов формообразования и самой архитектурной формы в свете новейших тенденций и достижений современной науки. Основные геометрические закономерности едины в естественном и антропогенном мире, в частности, в архитектуре и природе - живой и неживой, причём от микро- до макроуровня. Природный и антропогенный морфогенез происходит в физическом пространстве нашего мира с его неизбежными геометрическими и топологическими ограничениями. В современной архитектуре, как и всей экономической и социокультурной сфере, осуществляются весьма выраженные процессы глобализации и интернационализации, проявляющиеся конвергенцией в архитектурном формообразовании. Развитие пространственных форм было обусловлено достижениями подвижников, работавших на стыке инженерии и архитектуры. Новаторские формы зачастую возникают при интеграции и конвергенции научных достижений, инженерного искусства и архитектуры. Междисциплинарный подход и сравнительный анализ морфогенеза в архитектуре, технике, биологии и кристаллографии позволяют найти общие принципы формообразования на различных уровнях и в разных системах. Появляется возможность выявить универсальность построения оптимальных (по соотношению прочности и затрат материала, заполнению пространства) конструкций, создаваемых инженерами и архитекторами и самоорганизующихся в природе. За последние двадцать лет за работы в области кристаллографии (во многом геометрические) получены несколько Нобелевских премий по химии и физике [16; 19; 21]. Итак, новые подходы с использованием экспоненциально развивающихся технологий 
и результатов исследований параллелизма архитектурного и природного формообразования могут найти применение как в практике архитектуры и дизайна, так и в преподавании теории и истории архитектуры. Современный научный подход может быть применён для поиска архитектуры, адекватной природному и историческому контексту.

\section{Лuтература}

1. Пуанкаре, А. Наука и гипотеза / А. Пуанкаре; пер. А.В. Водянов. - М., 2003. - 209 с.

2. Вернадский, В.И. Биосфера и ноосфера / В.И. Вернадский - М. : Айрис-пресс, 2009. - 576 с.

3. Капра, Ф. Паутина жизни / Ф. Капра. - Киев : София, 2003. - 336 c.

4. Том, Р. Структурная устойчивость и морфогенез / Р. Том. - М. : Логос, 2002. -280 с.

5. Джан, Р.В. Филлотаксис: системное исследование морфогенеза растений / Р.В. Джан. - Москва-Ижевск : НИЦ «Регулярная и хаотическая динамика», Институт компьютерных исследований, 2006. - 464 с.

6. Mandelbrot, B.B. The Fractal Geometry of Nature / B.B. Mandelbrot - New York : Freeman, 1983.

7. Малинецкий, Г.Г. Хаос. Структуры. Вычислительный эксперимент. Введение в нелинейную динамику / Г.Г. Малинецкий. - М. : Наука, 1997. - 254 С.

8. Alsina, C. A Thousand Faces of Geometry: The Beauty of Polyhedra / C. Alsina. - RBA Coleccionables S.A., 2013. - 143 p.

9. Рутерсвард, 0. Невозможные фигуры / 0. Рутерсвард; под ред. Ю. Евсеевой. - М. : Стройиздат, 1990. - 128 с.

10. Кривошапко, С.Н. Энциклопедия аналитических поверхностей / С.Н. Кривошапко, В.Н. Иванов; Изд.стереотип. - URSS, 2015. - 560 c. ISBN 978-5-397-06693-8

11. Voronoi, G. Nouvelles applications des paramètres continus à la théorie des formes quadratiques / G. Voronoi // Reine Angewandte Mathem. - 1908. - № 133. - P. 97-178.

12. Baldwin, J. Bucky works /J. Baldwin. - New York: Wiley, 1996.

13. Том, Р. Математические модели морфогенеза / Р. Том. - М.-Ижевск : НИЦ «Регулярная и хаотическая динамика», Институт компьютерных исследований, 2006. - 136 с.

14. Ingber, D.E. Mechanical control of tissue growth: Function follows form / D.E. Ingber // Proceedings of the National Academy of Sciences USA, 2005. - V. 102. - P. 11571-11572.

15. Presnov E. Topological invariance of biological development / E. Presnov, V. Isaeva, N. Kasyanov // Axiomathes. - 2014. - № 24. - P. 117-135.

16. $\mathrm{C}_{60}$ : Buckminsterfullerene / Kroto H.W., Heath J.R., O'Brien S.C. [et al.] // Nature. - 1985. - № 318. P. 162-163.

17. Goldberg, M. A class of multi-symmetric polyhedral / M. Goldberg // Tohoku Mathematical Journal, First Series. - 1937. - № 43. - P. 104-108

18. Schein, S. Fourth class of convex equilateral polyhedron with polyhedral symmetry related to fullerenes and viruses / S. Schein, J.M. Gaye // Proceedings of the National Academy of
Sciences USA. - 2014. Vol. 111, Is. 8. - P. 2920-2925.

19. Electric Field Effect in Atomically Thin Carbon Films / K.S. Novoselov, A.K. Geim, S.V. Morozov [et al.] // Science. 2004. - № 306. P. 666-669.

20. Weaire, D. A counter-example to Kelvin's conjecture on minimal surfaces / D. Weaire, R. Phelan // Philosophical Magazine Letters. - 1994. - № 69. - P. 107-110.

21. Metallic phase withlong-range orientational order and no translational symmetry / D. Shechtman, I. Blech, D. Gratias, J.W. Cahn // Physical Review Letters. - 1984. - Vol. 53. - P. 1951-1954.

22. Скиннер, С. Священная геометрия. Расшифровывая код / С. Скиннер. - М. : Кладезь-Букс, 2007. - 160 с.

23. Гарднер, М. Этот правый, левый мир / М. Гарднер. - М. : Комкнига, 2007. - 272 с.

24. Касьянов, Н.В. Элементы фрактальности в архитектурном и природном формообразовании / Н.В. Касьянов // Академия. Архитектура и строительство. - 2007. - № 1. - С. 55-59; Касьянов, Н.В. Кристаллизация нанотехнологий в архитектуре / Н.В. Касьянов // Академия. Архитектура и строительство. 2012. - № 1. - С. 20-27; Касьянов, Н.В. Архитектура и «странный аттрактор» / Н.В. Касьянов // Современная архитектура мира. - Вып. 1 / Отв. ред. Н.А. Коновалова. -М., СПб. : Нестор-История, 2011. - 388 с., ил. - С. 175-190; Касьянов, Н.В. Образы природы в архитектурном формообразовании начала XXI века/ Н.В. Касьянов // Устойчивая архитектура: настоящее и будущее / Труды международного симпозиума, 17-18 ноября 2011 г. // Научные труды Московского архитектурного института (государственной академии) и группы КНАУФ-СНГ - М. : 000 «АделанТ», 2012. - С. 108-118; Касьянов, Н.В. 0 некоторых морфологическихаспектах современной архитектуры / Н.В. Касьянов // Современная архитектура мира. - Вып. 6 / Отв. ред. Н.А. Коновалова. - М., СПб: Нестор-История, 2016. - С. 69-81.

25. Banzhaf W. Artificial Life, Handbook of Natural Computing / W. Banzhaf, B. McMullin. Eds. G. Rozenberg [et al.] - Springer-Verlag : Berlin Heidelberg, 2012. - P. 1806-1834.

26. Langton, C.G. Artificial Life / C.G. Langton. -AddisonWesley Publ. Co., 1988.

\section{References}

1. Poincare A. Nauka i gipoteza [Science and hypothesis]. Moscow, 2003, 209 p. (In Russ.)

2. Vernadskii V.I. Biosfera i noosfera [Biosphere and Noospher]. Moscow, Airis-press Publ., 2009, 576 p. (In Russ.)

3. Kapra F. Pautina zhizni [Web of life]. Kiev, Sofiya Publ., 2003, 336 p. (In Russ.)

4. Tom R. Strukturnaya ustoichivost' i morfogenez [Structural stability and morphogenesis]. Moscow, Logos Publ., 2002, 280 p. (In Russ.)

5. Dzhan R.V. Fillotaksis: sistemnoe issledovanie morfogeneza rastenii [Fillotaxis: a systematic study of plant morphogenesis]. Moscow-Izhevsk: NITs «Regulyarnaya i khaoticheskaya dinamika», Institut komp'yuternykh issledovanii Publ., 2006, 464 p. (In Russ.)

6. Mandelbrot B.B. The Fractal Geometry of Nature [The Fractal 
Geometry of Nature]. New York, Freeman Publ., 1983. (In Engl.)

7. Malinetskii G.G. Khaos. Struktury. Vychislitel'nyi eksperiment. Vvedenie $v$ nelineinuyu dinamiku [Chaos. Structures. Computational experiment. Introduction to Nonlinear Dynamics]. Moscow, Nauka Publ., 1997, 254 p. (In Russ.)

8. Alsina C. A Thousand Faces of Geometry: the Beauty of Polyhedra. RBA Coleccionables S.A., 2013, 143 p. (In Engl.)

9. Rutersvard 0. Nevozmozhnye figury [Impossible figures], ed. Yu. Evseeva. Moscow Stroiizdat Publ., 1990, 128 p. (In Russ.)

10. Krivoshapko S.N., Ivanov V.N. Entsiklopediya analiticheskikh poverkhnostei [Encyclopedia of Analytic Surfaces]. Izd.stereotip. URSS Publ., 2015, 560 p. ISBN 978-5397-06693-8. (In Russ.)

11. Voronoi G. Nouvelles applications des paramètres continus à la théorie des formes quadratiques. Reine Angewandte Mathem, 1908, no. 133, pp. 97-178. (In France)

12. Baldwin J. Bucky works. New York, Wiley, 1996. (In Engl.)

13. Tom R. Matematicheskie modeli morfogeneza [Mathematical models of morphogenesis]. MoscowIzhevsk. NITs «Regulyarnaya i khaoticheskaya dinamika», Institut komp'yuternykh issledovanii Publ., 2006. 136 p. (In Russ.)

14. Ingber D.E. Mechanical control of tissue growth: Function follows form. Proceedings of the National Academy of Sciences USA, 2005, V. 102, pp. 11571-11572. (In Engl.)

15. Presnov E., Isaeva V., Kasyanov N. Topological invariance of biological development. Axiomathes, 2014, no. 24, pp. 117-135.

16. Kroto H.W., Heath J.R., O'Brien S.C., Curl R.F., Smalley R.E. $C_{60}$ : Buckminsterfullerene. Nature, 1985, no. 318, pp. 162-163. (In Engl.)

17. Goldberg M. A class of multi-symmetric polyhedral. Tohoku Mathematical Journal, First Series, 1937, no. 43, pp. 104-108. (In Engl.)

18. Schein S., Gaye J.M. Fourth class of convex equilateral polyhedron with polyhedral symmetry related to fullerenes and viruses. Proceedings of the National Academy of Sciences USA, 2014, Vol. 111, Is. 8, pp. 2920-2925. (In Engl.)

19. Novoselov K.S., Geim A.K., Morozov S.V., Jiang D., Zhang Y., Dubonos S.V., Grigorieva I.V., Firsov A.A. Electric Field Effect in Atomically Thin Carbon Films. Science, 2004, no. 306, pp.
666-669. (In Engl.)

20. Weaire D., Phelan R. A counter-example to Kelvin's conjecture on minimal surfaces. Philosophical Magazine Letters, 1994, no. 69, pp. 107-110. (In Engl.)

21. Shechtman D., Blech I., Gratias D., Cahn J.W. Metallic phase withlong-range orientational order and no translational symmetry. Physical Review Letters, 1984, Vol. 53, pp. 1951-1954. (In Engl.)

22. Skinner S. Svyashchennaya geometriya. Rasshifrovyvaya kod [Sacred geometry. Deciphering code]. Moscow, Kladez'-Buks Publ., 2007, 160 p. (In Russ.)

23. Gardner M. Etot pravyi,levyi mir [This right,left world]. Moscow, Komkniga Publ., 2007, 272 p. (In Russ.)

24. Kas'yanov N.V. Elementy fraktal'nosti v arkhitekturnom i prirodnom formoobrazovanii [Elements of fractality in architectural and natural shaping]. Akademiya. Arkhitektura i stroitel'stvo [Academia. Architecture and construction], 2007, no. 1, pp. 55-59. (In Russ.); Kas'yanov N.V. Kristallizatsiya nanotekhnologii v arkhitekture [Crystallization of nanotechnology in architecture]. Akademiya. Arkhitektura istroitel'stvo [Academia. Architecture and construction], 2012, no. 1, pp. 20-27/ (In Russ.); Kas'yanov N.V. Arkhitektura i «strannyi attraktor» [Architecture and "strange attractor"]. Sovremennaya arkhitektura mira [Modern architecture of the world], Vyp. 1, ed. N.A. Konovalova. Moscow, Saint Petersburg, Nestor-Istoriya Publ., 2011, 388 p., pp. 175-190. (In Russ.); Kas'yanov N.V. Obrazy prirody v arkhitekturnom formoobrazovanii nachala XXI veka [Images of nature in the architectural formation of the beginning of the 21 century]. Ustoichivaya arkhitektura: nastoyashchee i budushchee. Trudy mezhdunarodnogo simpoziuma, 17-18 noyabrya $2011 \mathrm{~g}$. [Sustainable architecture: present and future. Proceedings of the International Symposium, Moscow, November, 17-18, 2011]. KNAUF-SNG. Moscow, 000 “Adelant” Publ., 2012, pp. 108-118. (In Russ.); Kas'yanov N.V. 0 nekotorykh morfologicheskikh aspektakh sovremennoi arkhitektury [0n some morphological aspects of modern architecture]. Sovremennaya arkhitektura mira [Modern architecture of the world], Vyp. 6, ed. N.A. Konovalova. Moscow, St. Petersburg, Nestor-Istoriya Publ., 2016, pp. 69-81. (In Russ.);

25. Banzhaf W., McMullin B. Artificial Life, Handbook of Natural Computing. Eds. G. Rozenberg et al. Berlin-Heidelberg, Springer-Verlag Publ., 2012, pp. 1806-1834.

26. Langton C.G. Artificial Life. Addison-Wesley Publ. Co., 1988.

Касьянов Николай Владимирович (Москва). Кандидат архитектуры, советник РААСН. Ведущий научный сотрудник Научноисследовательского института теории и истории архитектуры и градостроительства (филиал ФГБУ «ЦНИИП Минстроя России» (111024, Москва, ул. Душинская, 9. НИИтИАГ). Эл.почта: kas_nv@mail.ru.

Kasyanov Nikolay Vladimirovich (Moscow). Ph. D. of architecture, adviser of RAASN. Leading Researcher at the Research Institute of Theory and History of Architecture and Urban Planning (9 Dushinskaya st., Moscow, 111024. NIITIAG), branch of the Central Institute for Research and Design of the Ministry of Construction and Housing and Communal Services of the Russian Federation (TsNIIP). E-mail: kas_nv@mail.ru. 